\title{
The value of $\mathrm{D}$-dimer in the detection of early deep-vein thrombosis after total knee arthroplasty in Asian patients: a cohort study Chung-Jen Chen ${ }^{1}$, Ching-Jen Wang*2 and Chung-Cheng Huang ${ }^{3}$
}

\begin{abstract}
Address: ${ }^{1}$ Department of Internal Medicine, Chang Gung Memorial Hospital-Kaohsiung Medical Center, Chang Gung University College of Medicine, Kaohsiung, Taiwan, ${ }^{2}$ Department of Orthopedic Surgery, Chang Gung Memorial Hospital-Kaohsiung Medical Center, Chang Gung University College of Medicine, Kaohsiung, Taiwan and ${ }^{3}$ Department of Diagnostic Radiology, Chang Gung Memorial Hospital-Kaohsiung Medical Center, Chang Gung University College of Medicine, Kaohsiung, Taiwan
\end{abstract}

Email: Chung-Jen Chen - chungjen@adm.cgmh.org.tw; Ching-Jen Wang* - w281211@adm.cgmh.org.tw; Chung-

Cheng Huang - cchuang@adm.cgmh.org.tw

* Corresponding author

Published: 28 May 2008

Thrombosis Journal 2008, 6:5 doi:10.1 186/1477-9560-6-5
Received: 30 October 2007

Accepted: 28 May 2008

This article is available from: http://www.thrombosisjournal.com/content/6/1/5

(C) 2008 Chen et al; licensee BioMed Central Ltd.

This is an Open Access article distributed under the terms of the Creative Commons Attribution License (http://creativecommons.org/licenses/by/2.0), which permits unrestricted use, distribution, and reproduction in any medium, provided the original work is properly cited.

\begin{abstract}
Background and purpose: The relationship of D-dimer and deep-vein thrombosis (DVT) after total knee arthroplasty (TKA) remains controversial. The purpose of this study was to assess the value of D-dimer in the detection of early DVT after TKA.

Methods: The measurements of plasma D-dimer level were obtained preoperatively and at day 7 postoperatively in 78 patients undergoing TKA. Ascending venography was performed in 7 to 10 days after surgery. The plasma D-dimer levels were correlated statistically with the venographic DVT.

Results: Venographic DVT was identified in $40 \%$ of patients. High plasma D-dimer level $>2.0 \mu \mathrm{g} /$ $\mathrm{ml}$ was found in $68 \%$ of patients with DVT and $45 \%$ without DVT $(P<0.05)$. Therefore, high Ddimer level greater than $2.0 \mu \mathrm{g} / \mathrm{ml}$ showed $68 \%$ sensitivity, $55 \%$ specificity, $60 \%$ accuracy, $50 \%$ positive predictive rate and $72 \%$ negative predictive rate in the detection of early DVT after TKA.

Conclusion: High plasma D-dimer level is a moderately sensitive, but less specific marker in the detection of early of DVT after TKA. Measurement of serum D-dimer alone is not accurate enough to detect DVT after TKA. Venography is recommended in patients with elevated D-dimer and clinically suspected but asymptomatic DVT after TKA.
\end{abstract}

\section{Background}

Recent studies have shown that the incidence of deep-vein thrombosis (DVT) after total knee arthroplasty (TKA) in Asian patients is as high as that of the Western countries [1-9]. Pharmaceutical prophylaxis significantly lowered the incidence of DVT, but none of currently available modalities showed total prevention of DVT [3]. Deep-vein thrombosis after TKA is sometimes difficult to diagnose because more than half of DVT cases after TKA are asymp- tomatic [3], which might cause propagation of the clots leading to pulmonary embolism [7]. Therefore, the effective management of DVT relies on the early detection of DVT. Venographic study is considered the gold standard in the diagnosis of DVT of the lower extremity. Venography, however, is an invasive procedure that can incur certain risks and is expensive [3]. As a result, patients often refuse venography and orthopedic surgeons thus are reluctant to recommend the procedure. Ultrasonography 
is a reasonable alternative, but the sensitivity of ultrasound in detecting calf DVT is inferior to venography and the examination is also expensive and time consuming $[10,11]$

Many studies of non-traumatized patients reported that the cross-linked fibrin degradation by-product associated with elevated D-dimer level is indicative of the presence of a clot, including DVT [8,12-26]. The measurement of Ddimer is simple, fast, convenient and inexpensive, and has the economic potential of reducing the use of more complex and expensive tests such as venography and ultrasonography. However, the interpretation of the D-dimer test in cases with DVT after TKA is still controversial [2733]. The purpose of this prospective study was to evaluate the value of plasma $\mathrm{D}$-dimer level in the detection of early DVT after TKA in Asian patients.

\section{Methods}

The Institutional Review Board of our hospital approved this study. All patients signed an informed consent. From January 2002 to June 2002, 89 consecutive patients undergoing TKA were enrolled in this study. Eleven patients were excluded because of incomplete data, only those taking D-dimer tests both prior to surgery and after surgery were enrolled. The remaining 78 patients were included in the final analysis. There were 64 females and 14 males with an average age of $67.3 \pm 8.6$ years (range 34 to 85 ). The mean body height was $151.3 \pm 7.5 \mathrm{~cm}$ (range 130 to 172 ), and the mean body weight was $67.0 \pm 12.1$ $\mathrm{kg}$ (range 47 to 110). The right knee was affected in 36 cases and the left knee in 42 . None of the patients had a family history of DVT. Routine preoperative work-ups included history and physical, complete blood count, coagulation profiles, chemistry profiles, electrocardiogram, and x-rays of the chest and knee. All operations were performed under either general or spinal anesthesia. Only one type of prosthesis (Advantim, Wright Medical, TN, USA) was used and all components were cemented. Prophylactic antibiotic (cefamezine) was given for 24 hours, but no pharmaceutical DVT prophylaxis was used because that pharmaceutical prohylaxis was not routinely used in most hospitals in our country. Therefore, we could study the natural occurrence of DVT and assess whether or not D-dimer can predict DVT development. All patients received the same protocol of postoperative management, including physical therapy with partial weight bearing on the operated leg, muscle exercise and continuous passive motion (CPM) starting on the second postoperative day. Patients were discharged from the hospital when they were independent on ambulation with a walking aid, and continued outpatient physiotherapy until full recovery.

Blood samples for plasma D-dimer measurement were drawn on the day before surgery and the $7^{\text {th }}$ day after sur- gery. The measurements of plasma D-dimer level were performed with the D-dimer plus (DADE BEHRING, Marburg, Germany) by microlatex assay, which using a monoclonal antibody to detect only cross-linked D-dimer fragments. The total range of D-dimer measurements extended from 0.05 to $6.5 \mu \mathrm{g} / \mathrm{ml}$. The D-dimer levels were defined as negative $(<0.25 \mu \mathrm{g} / \mathrm{ml})$, minimal $(0.25-0.5$ $\mu \mathrm{g} / \mathrm{ml})$, low $(0.5-1.0 \mu \mathrm{g} / \mathrm{ml})$, medium $(1.0-2.0 \mu \mathrm{g} / \mathrm{ml})$ and high $(>2.0 \mu \mathrm{g} / \mathrm{ml})$. Ascending venography was performed in 7 to 10 days postoperatively. The venographies were interpreted for DVT by two radiologists blinded to the nature of the study.

\section{Statistical analysis}

The data of D-dimer levels were statistically correlated with the occurrence of venographic DVT using Chi Square test with statistical significance set at $\mathrm{P}<0.05$.

\section{Results}

\section{The prevalence of DVT}

DVT was identified in 31 of 78 patients resulting in an incidence of $40 \%$. There were $30(97 \%)$ distal and one proximal DVT (3\%). There was no pulmonary embolism. Symptomatic DVT including pain and swelling of the leg or skin discoloration and calf or thigh girth enlargement was observed in 9 patients $(29 \%)$ with positive venographic DVT. The remaining 22 cases $(71 \%)$ were asymptomatic.

\section{D-dimer level}

The results of plasma D-dimer level before and after surgery are shown in Fig. 1. Before surgery, 20 of 78 patients $(26 \%)$ showed positive D-dimer reaction, although high D-dimer level of greater than $2.0 \mu \mathrm{g} / \mathrm{ml}$ was noted in only one patient (1.3\%). After surgery, all 78 patients showed positive D-dimer reaction including 43 patients (55\%) with D-dimer level of greater than $2.0 \mu \mathrm{g} / \mathrm{ml}$ and 35 patients (45\%) with lower D-dimer level of less than 2.0 $\mu \mathrm{g} / \mathrm{ml}$. The plasma D-dimer levels in patients with and without DVT are shown in Fig. 2. Thirty-one patients (40\%) developed DVT postoperatively whereas 47 patients did not.

\section{D-dimer level and DVT}

The correlations of D-dimer level and the occurrence of venographic DVT are shown in Table 1. High plasma Ddimer level of greater than $2.0 \mu \mathrm{g} / \mathrm{ml}$ was noted in $68 \%$ (21 of 31 ) of patients with positive DVT versus $45 \%$ (21 of 47) of patients without DVT $(\mathrm{P}<0.05)$. Lower plasma D-dimer level (less than $2.0 \mathrm{ug} / \mathrm{ml}$ ) was seen in $32 \%(10$ of 31) of patients with DVT and 55\% (26 of 47) of patients without DVT. 


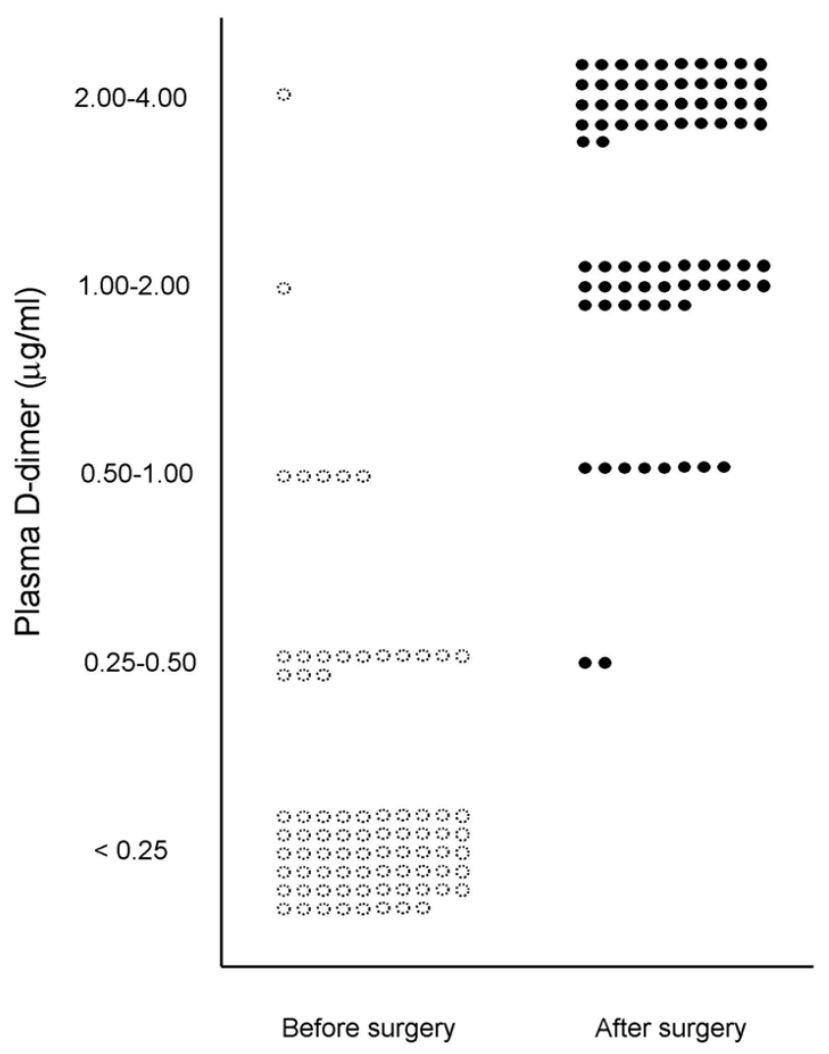

Figure I

The plasma D-dimer levels before and after total knee arthroplasty.

The sensitivity and specificity of D-dimer level in DVT The calculations of sensitivity, specificity, accuracy, positive and negative predictive values of plasma D-dimer level in the detection of early DVT are shown in Table 1. When high plasma D-dimer level $(>2.0 \mu \mathrm{g} / \mathrm{ml})$ is used as a biological marker for early DVT after TKA, sensitivity is $68 \%$, specificity is $55 \%$, accuracy is $60 \%$, positive predictive rate is $50 \%$ and negative predictive rate is $72 \%$.

\section{Discussion}

Clinical diagnosis of DVT is unreliable. In symptomatic DVT, compression ultrasound is very accurate [34]. However, patients with asymptomatic DVT frequently showed normal ultra sonography $[13,22]$. Ascending venography

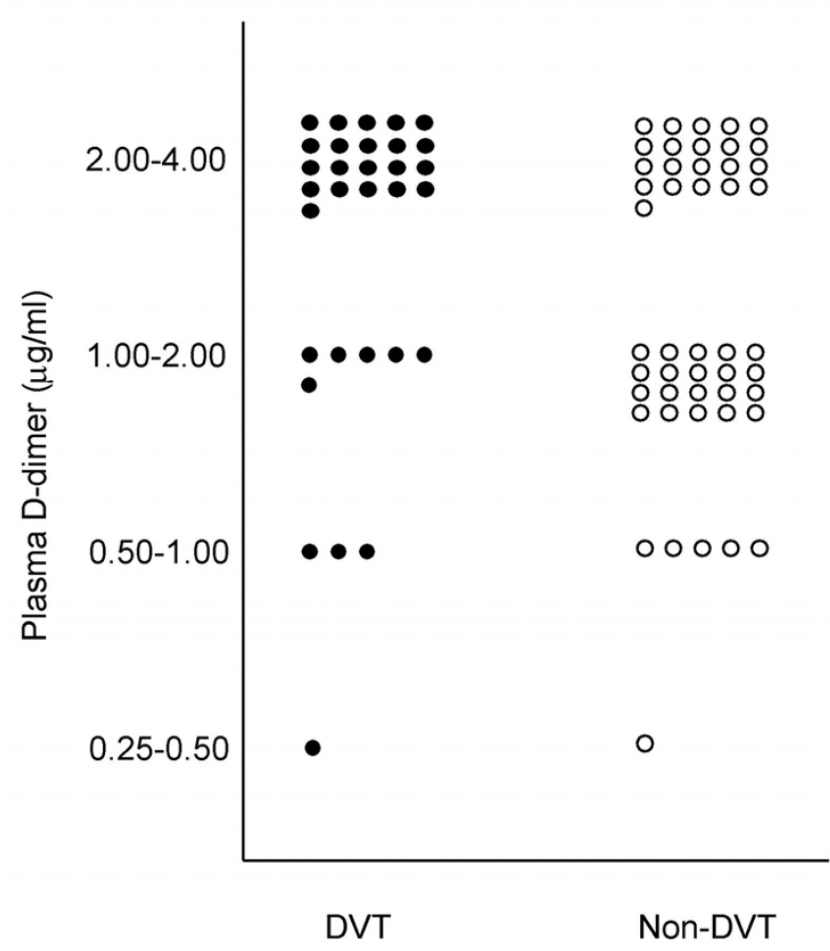

Figure 2

The plasma D-dimer levels in patients with and without deep-vein thrombosis after total knee arthroplasty.

is the most reliable method in the detection of DVT of the lower leg, but it is expensive, time consuming and incurs certain risks [3]. The D-dimer test might be an attractive alternative in early detection of DVT. Many studies of nontraumatized patients reported that the plasma D-dimer assay is indicative of DVT. However, the value of D-dimer in DVT after TKA remains controversial. Shiota el al reported that a high level of $\mathrm{D}$-dimer on the $7^{\text {th }}$ postoperative day was most sensitive with $95.5 \%$ for THA and $94.4 \%$ for TKA and most specific with $96.9 \%$ for THA and 90.0\% for TKA in the diagnosis of DVT after THA and TKA, and concluded that high level of D-dimer on postoperative day 7 [27]. Arnesen et al reported a correlation of Ddimer with late occurring DVT at day 35 after hip replacement surgery [28]. On the contrary, other studies reported a negative value of D-dimer in the diagnosis of DVT after TKA [29-33]. Bounameaux et al [29] reported that meas-

Table I: Sensitivity and specificity of different D-dimer levels in DVT after TKA

\begin{tabular}{|c|c|c|c|c|}
\hline D-dimer level & DVT N = 3I & Non-DVT N = 47 & Sensitivity \% & Specificity \% \\
\hline$>0.25 \mathrm{ug} / \mathrm{ml} \mathrm{VS}<0.25 \mathrm{ug} / \mathrm{ml}$ & 31 VS 0 & 47 VS 0 & 100 & 0 \\
\hline$>0.5 \mathrm{ug} / \mathrm{ml} \mathrm{VS}<0.5 \mathrm{ug} / \mathrm{ml}$ & 30 VS I & 46 VS I & 97 & 2 \\
\hline$>$ ug $/ \mathrm{ml} \mathrm{VS}<$ l ug/ml & 27 VS 4 & $4 I$ VS 6 & 87 & 13 \\
\hline$>2 \mathrm{ug} / \mathrm{ml} \mathrm{VS}<2 \mathrm{ug} / \mathrm{ml}$ & $21 \mathrm{VS} 10$ & 21 VS 26 & 68 & 55 \\
\hline
\end{tabular}


Table 2: Comparison of D-dimer and DVT after TKA among different studies

\begin{tabular}{|c|c|c|c|c|c|}
\hline Place & Author & $N$ & Sensitivity\% & Specificity\% & reference \\
\hline Japan & Shiota et al & 28 & 94 & 90 & [27] \\
\hline Switzland & Bounameaux & 118 & 73 & 37 & [29] \\
\hline France & De Prost & 11 & 100 & 0 & [32] \\
\hline France & Abraham & 188 & 57 & 71 & [33] \\
\hline Taiwan & Chen et al & 78 & 68 & 55 & present study \\
\hline
\end{tabular}

urement of plasma D-dimer concentration is of no value for predicting, diagnosing or ruling out DVT in patients undergoing total knee arthroplasty. Harper et al [30] stated that the SimpliRED assay in D-dimer measurement is too insensitive to use as a reliable exclusion test in cases of suspected DVT.

The results of the current study showed that high plasma D-dimer level of higher than $2.0 \mu \mathrm{g} / \mathrm{ml}$ at day 7 postoperatively is moderately sensitive, but not necessarily specific enough in the detection of early DVT after TKA. The findings of the current study are in agreement with those of the European reports, but different from the findings of Japanese study (Table 2). The results of the study suggested that D-dimer test alone is not accurate enough in the detection of early DVT because the plasma D-dimer level can be influenced by comorbid conditions such as cancer, infection and surgery [14].

\section{Conclusion}

Measurement of plasma D-dimer level is not accurate enough in detecting DVT after TKA. Venography is recommended in patients with elevated D-dimer and clinically suspected but asymptomatic DVT after TKA.

\section{Competing interests}

The authors declare that they have no competing interests.

\section{Authors' contributions}

CJC participated in the study with the analysis of data and review of the references.

CJW participated in the study with contribution of the study design and manuscript preparation.

$\mathrm{CCH}$ participated in the study with interpretation and analysis of venography.

All authors read and approved the final manuscript.

\section{Acknowledgements}

We thank Miss Ya-Hsueh Chuang for assistance in the preparation of this manuscript.

\section{References}

I. Dhillon KS, Askander A, Doralsmay S: Postoperative deep-vein thrombosis in Asian patients is not a rarity: a prospective study of 88 patients with no prophylaxis. J Bone Joint Surg (Br) 1996, 78-B:427-30.

2. Kim YH, Kim JS: Incidence and natural history of deep-vein thrombosis after total knee arthroplasty. A prospective, randomized study. J Bone Joint Surg Br 2202, 84-B:566-70.

3. Wang CJ, Wang JW, Weng LS, Hsu CC, Huang CC, Yu PC: Prevention of deep-vein thrombosis after total knee arthroplasty in Asian patients. Comparison of prophylaxis with low molecular weight heparin and indomethacin. J Bone Joint Surg (Am) 2004, 86-A: I 36-I 40.

4. Colwell CW Jr: Low molecular weight heparin prophylaxis in total knee arthroplasty: the answer. Clin Orthop 200I, 392:245-8.

5. Leizorovicz A, Turpie AG, Cohen AT, Wong L, Yoo MC, Dans A: Epidemiology of venous thromboembolism in Asian patients undergoing major orthopedic surgery without thromboprophylaxis. The SMART study. J Thromb Haemost 2005, 3:28-34.

6. Lotke PA, Steinberg ME, Ecker ML: Significance of deep venous thrombosis in the lower extremity after total joint arthroplasty. Clin Orthop 1994, 299:25-30.

7. Maynard MJ, Sculco TP, Ghelman B: Progression and regression of deep vein thrombosis after total knee arthroplasty. Clin Orthop 1991, 273: 125-30.

8. Miric A, Lombardi P, Sculco TP: Deep vein thrombosis prophylaxis: a comprehensive approach for total hip and total knee arthroplasty patient populations. Am / Orthop 2000, 29:269-74.

9. Piovella F, Wang CJ, Lu H, Lee K, Lee LH, Lee WC, Turpie AGG, Gallus AS, Planès A, Passera R, Rouillon A: Deep-vein thrombosis rates after major orthopedic surgery in Asia. An epidemiological study based on postoperative screening with centrally adjudicated bilateral venography. J Thromb Haemost 2005, 3:2664-2670

10. Wang CJ, Huang CC, Yu PC, Chen HH: Diagnosis of deep venous thrombosis after total knee arthroplasty: A comparison of ultrasound and venography studies. Chang Gung Med J 2004, 27:16-2I.

II. Schellong SM, Beyer J, Kakkar AK, Halbritter K, Eriksson BI, Turpie $A G$, Misselwitz F, Kalebo P: Ultrasound screening for asymptomatic deep vein thrombosis after major orthopaedic surgery: the VENUS study. J Thromb Haemost 2007, 5: I43I-7.

12. Anderson DR, Wells PS, Stiell I, MacLeod B, Simms M, Gray L, Robinson KS, Bormanis J, Mitchell M, Lewandowski B, Flowerdew G: Management of patients with suspected deep vein thrombosis in the emergency department: combining use of a clinical diagnosis model with D-dimer testing. J Emerg Med 2000, 19:225-30.

13. Andreescu AC, Cushman M, Rosendaal FR: D-dimer as a risk factor for deep vein thrombosis: the Leiden Thrombophilia Study. Throm Haemo 2002, 87:47-5I.

14. Aschwanden M, Labs KH, Jeanneret C, Gehrig A, Jaeger KA: The value of rapid $D$-dimer testing combined with structured clinical evaluation for the diagnosis of deep vein thrombosis. J Vas Surg 1999, 30(5):929-35.

15. Crippa L, D'Angelo SV, Tomassini L, Rizzi B, D'Alessandro G, D'Angelo $A$ : The utility and cost-effectiveness of $D$-dimer measurements in the diagnosis of deep vein thrombosis. Haematologica 1997, 82:446-51. 
16. D'Angelo A, D'Alessandro G, Tomassini L, Pittet JL, Dupuy G, Crippa $L$ : Evaluation of a new rapid quantitative $D$-dimer assay in patients with clinically suspected deep vein thrombosis. Thromb Haemost 1996, 75(3):412-6.

17. Declerck PJ, Mombaerts P, Holvoet P, De Mol M, Collen D: Fibrinolytic response and fibrin fragment $D$-dimer levels in patients with deep vein thrombosis. Thromb Haemost I 987, 58(4): I024-9.

18. Harvey RL, Roth EJ, Yarnold PR, Durham JR, Green D: Deep vein thrombosis in stroke. The use of plasma D-dimer level as a screening test in the rehabilitation setting. Stroke 1996, 27:1516-20.

19. Heaton DC, Billings JD, Hickton CM: Assessment of D dimer assays for the diagnosis of deep vein thrombosis. J Lab Clin Med 1987, I I0:588-91.

20. Larsen TB, Stoffersen E, Christensen CS, Laursen B: Validity of Ddimer tests in the diagnosis of deep vein thrombosis: a prospective comparative study of three quantitative assays. J Intern Med 2002, 252(I):36-40.

21. Legnani C, Pancani C, Palareti G, Guazzaloca G, Fortunato G, Grauso $F$, Golfieri R, Gianpalma E, Coccheri S: Comparison of new rapid methods for D-dimer measurement to exclude deep vein thrombosis in symptomatic outpatients. Blood Coagul Fibrinolysis 1997, 8(5):296-302.

22. Legnani C, Pancani C, Palareti G, Guazzaloca G, Coccheri S: Contribution of a new, rapid, quantitative and automated method for D-dimer measurement to exclude deep vein thrombosis in symptomatic outpatients. Blood Coagul Fibrinolysis 1999, I0(2):69-74.

23. Lennox AF, Delis KT, Serunkuma S, Zarka ZA, Daskalopoulou SE, Nicolaides AN: Combination of a clinical risk assessment score and rapid whole blood D-dimer testing in the diagnosis of deep vein thrombosis in symptomatic patients. J Vasc Surg 1999, 30(5):794-803.

24. Watanabe R, Wada H, Mori Y, Nakasaki T, Sawa H, Shiku H: Plasma D-dimer levels in patients with deep vein thrombosis. Ja J Clin Path 1999, 47:887-90.

25. Wells PS, Brill-Edwards Patrick, Stevens P, Panju A, Patel A, Douketis J, Massicotte MP, Hirsh J, Weitz Jl, Kearon C, Ginsberg JS: A novel and rapid whole-blood assay for D-dimer in patients with clinically suspected deep vein thrombosis. Circulation 1995, 91:2184-7.

26. Wells PS, Anderson DR, Rodger M, Forgie M, Kearon C, Dreyer J, Kovacs G, Mitchell M, Lewandowski B, Kovacs MJ: Evaluation of Ddimer in the diagnosis of suspected deep-vein thrombosis. New Eng J Med 2003, 349: 1227-35.

27. Shiota N, Sato T, Nishida K, Matsuo M, Takahara Y, Mitani S, Murakami T, Inoue H: Changes in LPIA D-dimer levels after total hip or knee arthroplasty relevant to deep-vein thrombosis diagnosed by bilateral ascending venography. J Orthop Sci 2002, 7(4):444-50.

28. Arnesen H, Dahl OE, Aspelin T, Seljeflot I, Kierulf $P$, Lyberg T: Sustained prothrombotic profile after hip replacement surgery: the influence of prolonged prophylaxis with dalteparin. J Thromb Haemost 2003, I(5):971-5.

29. Bounameaux H, Miron MJ, Blanchard J, de Moerloose P, Hoffmeyer P, Leyvraz PF: Measurement of plasma D-dimer is not useful in the prediction or diagnosis of postoperative deep vein thrombosis in patients undergoing total knee arthroplasty. Blood Coagula Fibri 1998, 9:749-52.

30. Harper P, Marson C, Grimmer A, Monahan K, Humm G, Baker B: The rapid whole blood agglutination $d$-dimer assay has poor sensitivity for use as an exclusion test in suspected deep vein thrombosis. NZ Med J 200I, I I 4( I I 26):6I-4.

31. Mazzolai L, Haesler E, Milesi I, Hayoz D: D-dimer testing is not recommended for the exclusion of deep vein thrombosis in outpatients with lower limb erysipelas. Throm Haemo 2002, 88:880.

32. De Prost D, Ollivier V, Vie P, Benacerraf R, Duparc J, Khoury A: Ddimer and thrombin-antithrombin III complex levels uncorrelated with phlebographic findings in II total knee replacement patients. Ann Biol Clin (Paris) 1990, 48:235-8.

33. Abraham P, Ternisien C, Hubert L, Pidhorz L, Saumet JL: Does venous microemboli detection and to the interpretation of D-dimer values following orthopedic surgery? Ultrasound Med Biol 1999, 25:637-40.
34. Lensing AW, Prandoni P, Brandjes D, Huisman PM, Vigo M, Tomasella G, Krekt J, Wouter Ten Cate J, Huisman MV, Buller HR: Detection of deep-vein thrombosis by real-time B-mode ultrasonography. N Engl J Med 1989, 320:342-5.
Publish with Biomed Central and every scientist can read your work free of charge

"BioMed Central will be the most significant development for disseminating the results of biomedical research in our lifetime. "

Sir Paul Nurse, Cancer Research UK

Your research papers will be:

- available free of charge to the entire biomedical community

- peer reviewed and published immediately upon acceptance

- cited in PubMed and archived on PubMed Central

- yours - you keep the copyright 